\title{
CRIMSONpublishers
}

http://www.crimsonpublishers.com

Clinical Image

ISSN: $2640-9208$

\section{Skeletal Imaging of Nutritional Disorders in Children}

\author{
Kakarla Subbarao* \\ KIMS Foundation and Research Centre, India
}

*Corresponding author: Kakarla Subbarao, MS, D.Sc. (HON), FRCR, FACR, FICP, FSASMA, FCCP, FICR, FCGP, Chairman, KIMS Foundation and Research Centre, Minister road, Sec- 500003, Telangana, India

Submission: September 06, 2017; Published: January 22, 2018

\begin{abstract}
Imaging of skeleton plays a major role in the diagnosis of nutritional disorders in children. The disorders can be

1) Deficiency and

2) Toxic (Overdose).

The common deficiency disorders include rickets, scurvy, osteoporosis and anemias. Conventional radiology is adequate in the diagnosis, except in the grading of diagnosis of degrees of osteoporosis. The differential diagnosis is also discussed.
\end{abstract}

Keywords: Rickets, scurvy; Osteoporosis; Fluorosis; Lead poisoning; Vitamin A and D overdose; Radiological characteristics

\section{Introduction}

Despite governmental and nongovernmental service programs in improving pediatric nutrition with supplementary foods, it is not uncommon to see children with nutritional deficiency disorders. Most of them reflect upon the musculoskeletal system. The major deficiency disorders include nutritional rickets, scurvy, osteoporosis, hypoprotenemia and anemias. The conventional radiological appearances are classical and very rarely are it needed to have advanced imaging methods. However, quantitative computed tomography (CT), dual-energy photon absorptiometry, and dualenergy x-ray absorptiometry, which are reliable measurement methods to assess the degree of osteoporosis. Rarely this is used in pedeatric practice. The conventional radiological characteristics are described in detail supported by illustrations. The differential diagnosis and their varied radiological appearances are mentioned. Rickets can be encountered in neonatal, childhood and adolescents.

\section{Radiological Findings and Review of the Literature}

\section{Rickets}

Table 1: The etiological and metabolic factors of rickets.

\begin{tabular}{|c|}
\hline The Etiological and Metabolic Factors of Rickets \\
\hline The etiological and metabolic factors of rickets \\
\hline Dietary - Deficiency of vitamin D, calcium and phosphorus \\
\hline Mal absorption - Hepatobiliary disorders, hereditary pancreatitis and gastrointestinal surgeries \\
\hline Nonutilization - Liver disorders, interfering with first stage of vitamin D metabolism. \\
\hline Kidney disorders - Proximal and distal tubular acidosis, chronic renal disorders interfering with final stage of vitamin D metabolism. \\
\hline
\end{tabular}

The toxic disorders include hypervitaminosis A and D. Other causes include plumbism, hypercalcemia, steroids, heparin over use, antiepiliptic drugs and flurosis.

\section{Pathophysiology of Rickets}

The deposition of mineral in cartilage needs adequate amounts of both calcium and phosphorous. If these are deficient failure of new bone mineralization takes place. The resorption of unmineralized osteoid is less due to inhibition of osteoclastic resorption of matrix. As a result the skeleton becomes soft resulting in deformities in fractures. In rickets normal amount of bone has rarely adequate time to accumulate and hence the patient has both osteoporosis and osteomalacia. Osteoid excess in the growing cartilage results in widening of growth plate. During the process of healing the islands of unremodelled cartilage remain in the metaphyseal zone resulting in patches, resulting in lytic appearances on radiography. 
An age old disorder principally affects the growing cartilage and bone. This is equivalent to osteomalacia in adults [1-5]. The etiological and metabolic factors of rickets include the following (Table 1)

There are three types of rickets related to vitamin D,
1) Vitamin D Deficient,

2) Vitamin D Dependant and

3) Vitamin D Resistant. Radiological findings of nutritional rickets are listed in (Table 2).

Table 2: Rickets (Radiological Findings).

\begin{tabular}{|c|c|c|c|c|}
\hline Rickets & Delayed growth and maturation \\
\hline Widening of growth plate due to osteoid excess Metaphyseal cupping \\
\hline Cortical spurs projecting at right angles to metaphysis \\
\hline Coarse trabeculation / accentuation of primary trabeculae \\
\hline "Paint Brush" metaphyses \\
\hline Osteoid seams \\
\hline Rachitic rosary of ribs \\
\hline Frontal bossing of skull \\
\hline Generalized osteoporosis. \\
\hline
\end{tabular}

Rickets (Radiological findings)

Table 3: Radiological findings of the Skull and Spine.

\begin{tabular}{|c|}
\hline Skull changes in florid rickets \\
\hline Pronounced calvarial demineralization (Even facial bones are involved) \\
\hline Basilar Invagination \\
\hline Indistinct sutural margin \\
\hline Delayed tooth eruption \\
\hline Premature craniostenosis \\
\hline Craniotabes \\
\hline Calvarial thickening following treatment \\
\hline Spine changes \\
\hline Scoliosis \\
\hline Biconcave vertebral bodies \\
\hline Triradiate pelvis \\
\hline
\end{tabular}

The most severely affected long bones include distal femur, the proximal tibia, distal radius, ulna and proximal end of the humerus which are actively growing ends of the bones. In long-standing rickets, bowing of weight bearing bones and increased incidence of fractures for which surgical correction may be required [6].

Radiological findings of the Skull and Spine are included in Table 3. These are less severe as compared with growing long bones.

\section{Neonatal Rickets}

In first 2 years of life, incidence of Rickets is 5 to $20 \%$. Neonatal rickets is believed to be of multifactorial origin. Major contributing factors are related to nutrition, immaturity of enzyme systems \& iatrogenic/ metabolic factors. Premature infants of low birth weight are primarily affected. Bony changes appear around 2 months of age. The most frequent causes of Rickets in patients under 6 months of age also include conditions like Biliary Atresia (Figure 1).

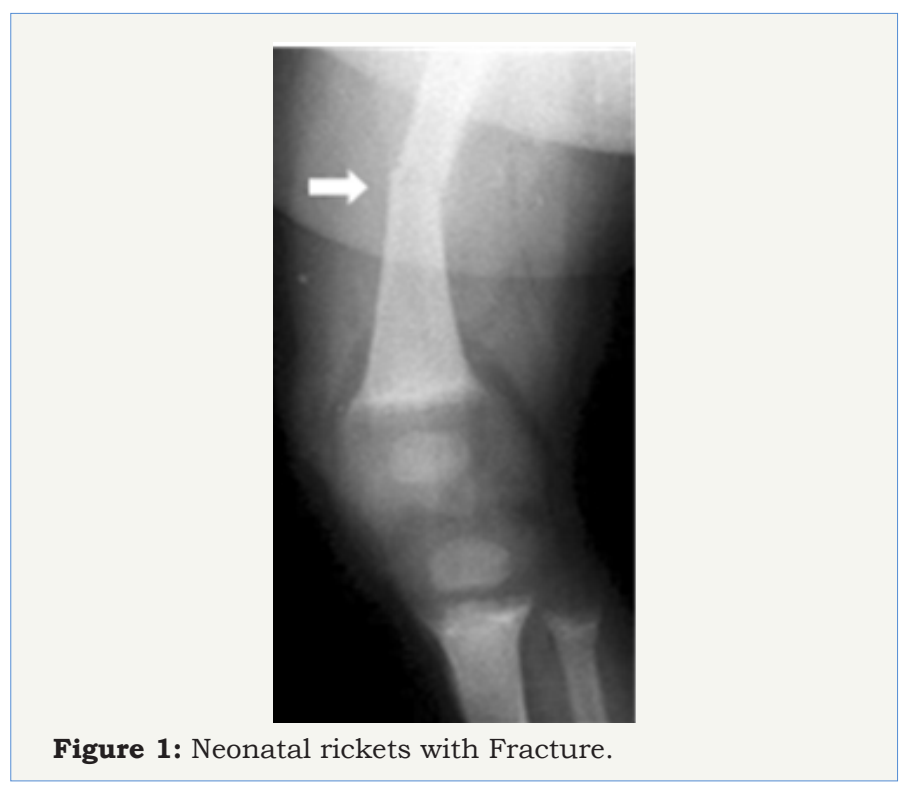

Figure 1: Neonatal rickets with Fracture. 


\section{Rickets}
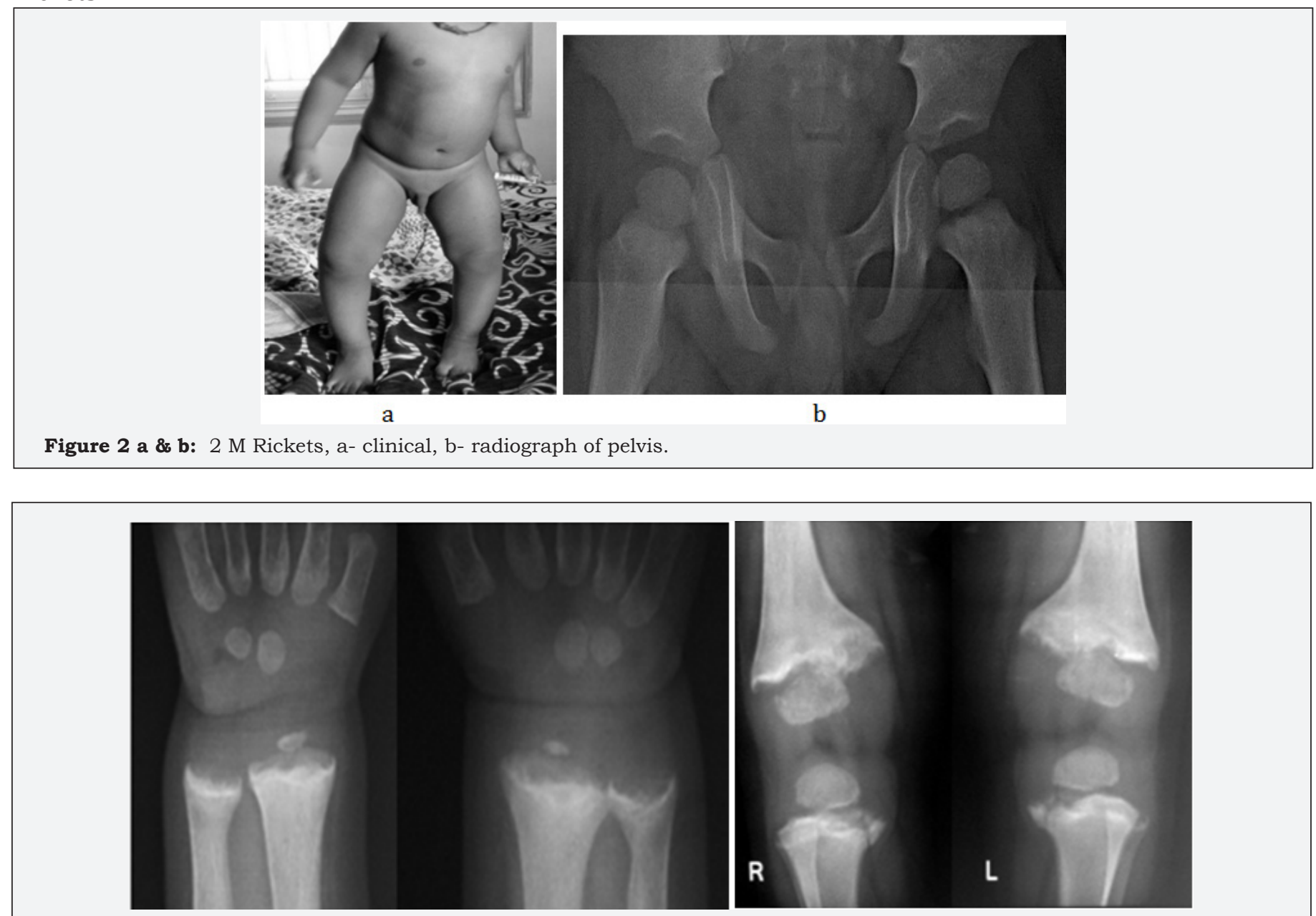

Figure 2 c \& d: $1 \frac{1}{1 / 2}$ yrs, Rickets, a- hands, b- knees.

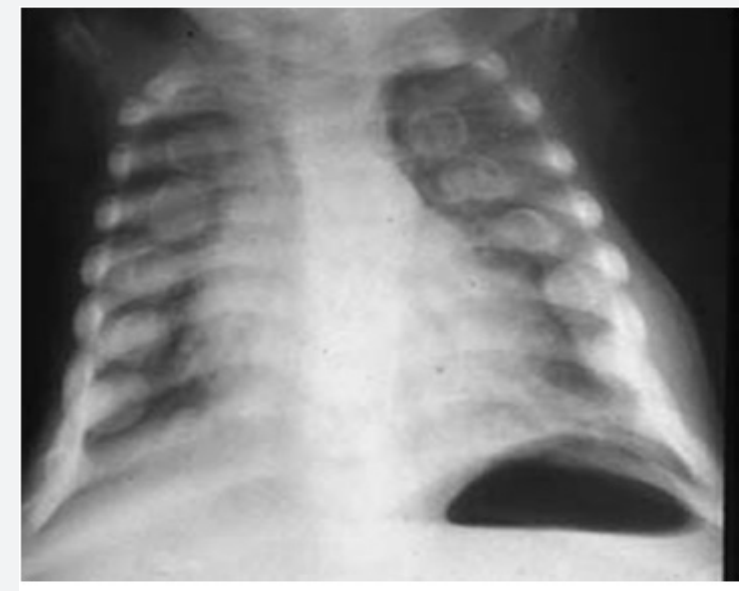

e

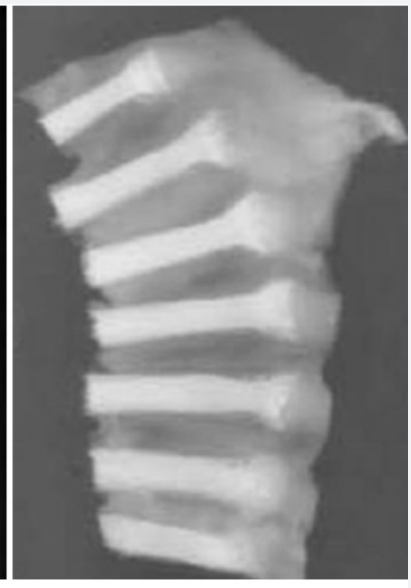

f

Figure 2 e $\&$ f: Rachitic rosary, a- chest, b- specimen of ribs.

In young children and adolescents, characteristic radiological appearances are noted on conventional films. These include osteoporosis, metaphyseal cupping and ground glass appearance of growing and weight bearing bones (Figure 2a-2d). Rachitic rosary deformity is common in the chest with cupping of the costochondral junctions (Figure 2e \& 2f).

Bowing deformities and knock knees are common in the lower extremities (Figure 3a-3c). 


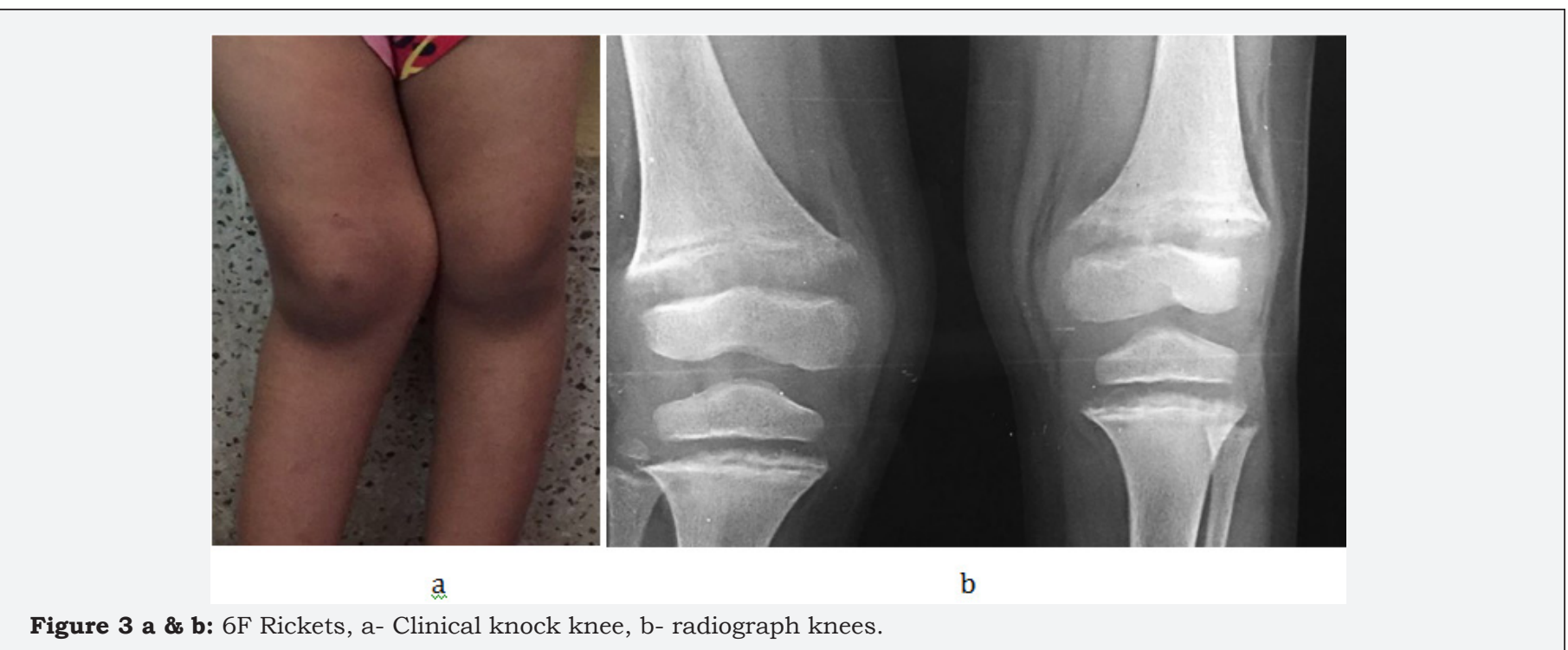

Figure 3 a \& b: 6F Rickets, a- Clinical knock knee, b- radiograph knees.

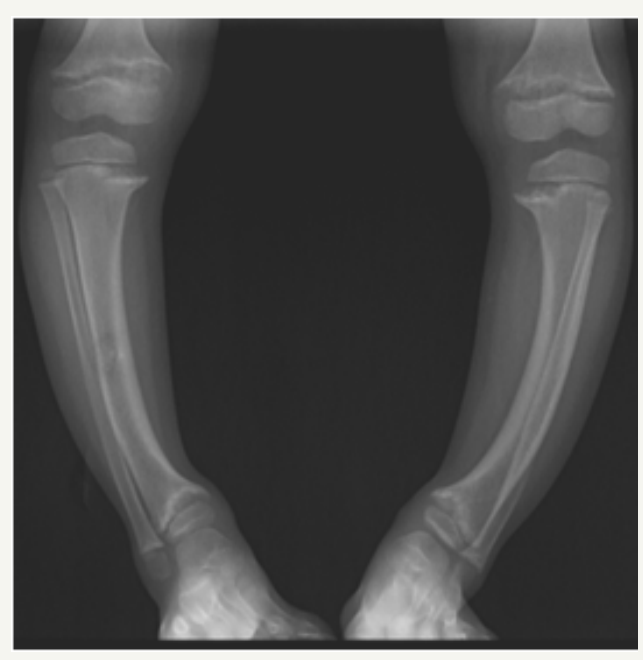

Figure 3c: Rickets with bowed legs

\section{Healing Rickets}

With Vitamin D and calcium treatment, regression of radiological findings is noted. During healing, radiolucent bands at metaphyses of long bones become sclerotic. Cupping of metaphyses become clearly prominent. As healing progresses remodelling of bowing deformities occur. In skull, characteristic bossing of frontal \& parietal bones becomes apparent (Figure 4a-4d). There may be with premature closure of sutures.

\section{Sequelae Post-Rickets}

Complete healing and restoration of normal structures occurs in nutritional rickets. However distortion/sclerosis of spongiosa in affected segment may occur after healing \& may remain visible for several years. Cortical thickening of segments of bone involved during active stage also may persist. Angular deformities secondary to pathological fractures result in deformities like knock-knee, bow leg and sabre shin (Figure 5).

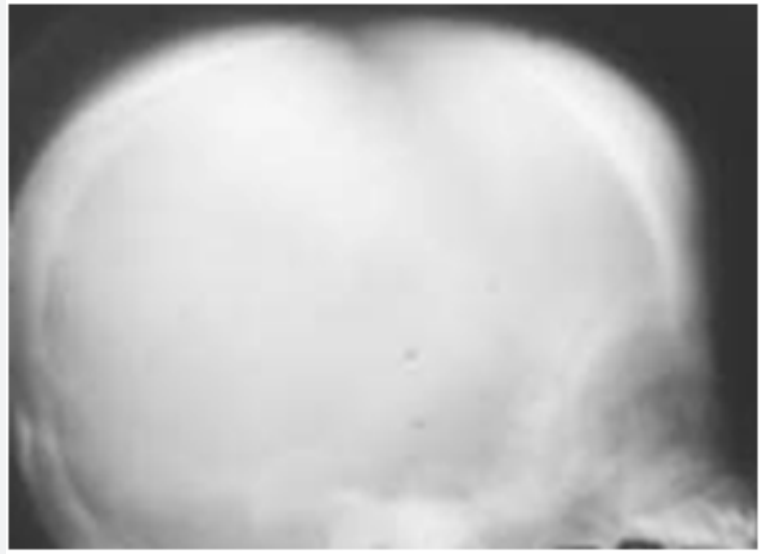

a

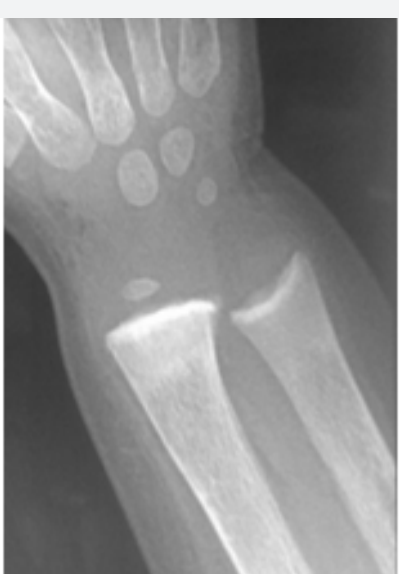

b

Figure 4 a \& b: Healing Rickets, a- lateral skull and b- Wrist. 


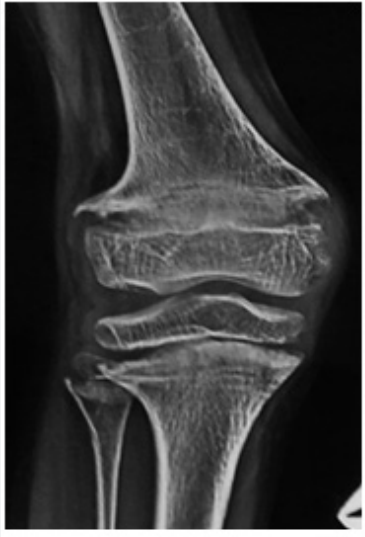

C

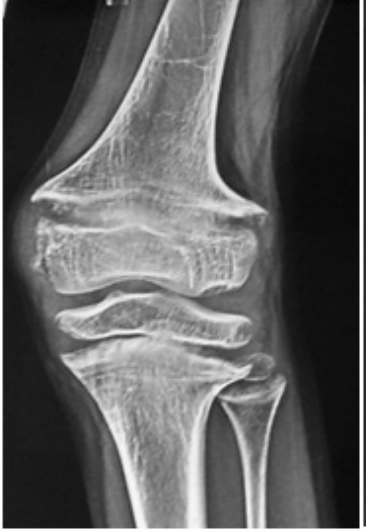

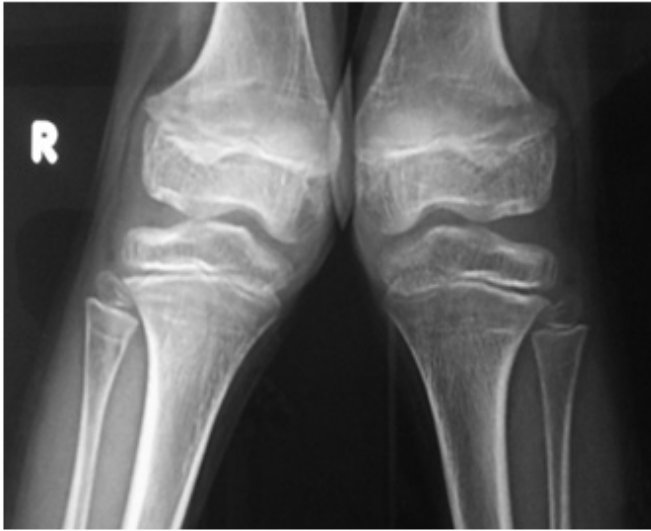

d

Figure 4 c \& d: Rickets, a- active, b- healed.

Signs of healing are listed in Table 4.

Table 4: Signs of healing.

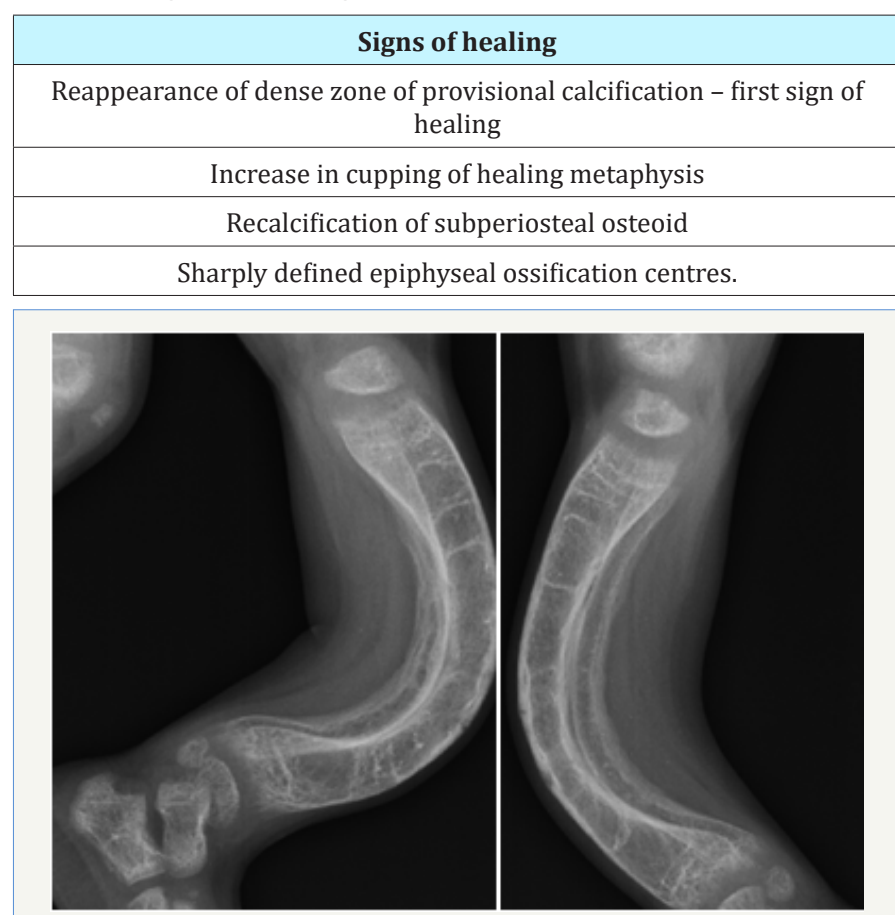

Figure 5: Healing rickets bowing of the tibiae.

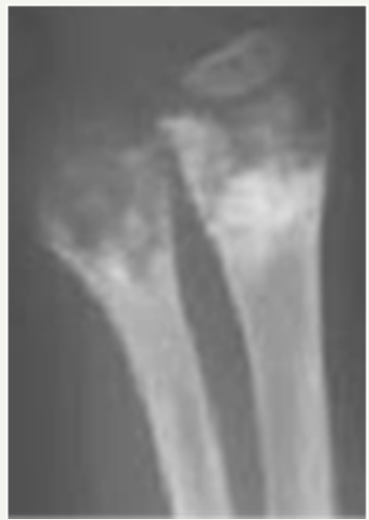

Figure 6: Hypophospatasia in a child.
Radiological findings of nutritional rickets are almost the same in other forms of rickets. In the Differential diagnosis, Hypophospatasia (low serum alkaline phosphatase) and metaphyseal chondrodyplasia (type schmid). Hypophospatasia may be encountered in neonates, children, adolescents and adults. Radiographics manifestations are different according to ages [7]. Deep cupping with irregularity of metaphyses is a common finding in children, simulating healing rickets (Figure 6).

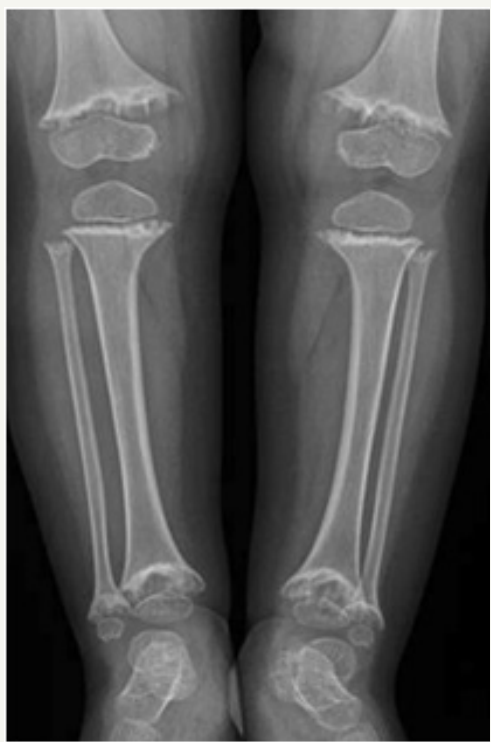

Figure 7: Metaphyseal dysplasia simulating rickets.

Metaphyseal chondrodysplasia is a rare genetic abnormality with no Vitamin D abnormality. There is generalized symmetric disturbance of enchondral bone formation. Radiologically, the metaphysic are well mineralized and may have increased density with irregular margins, simulating healing rickets7. Serum calcium, phosphorus and alkaline phosphatase are normal (Figure 7).

\section{Scurvy}

Scurvy, which in infants is also known as Barlow disease, is a disorder caused by dietary lack of vitamin $\mathrm{C}$ and characterised by increased bleeding tendency and impaired collagen synthesis 
resulting in osteoporosis and impaired wound healing. Today, scurvy is very rare due to consumption of qualitative foods in pregnant mothers as well as in infants. The radiographic features are listed in Table $5[1,3,4,7]$.

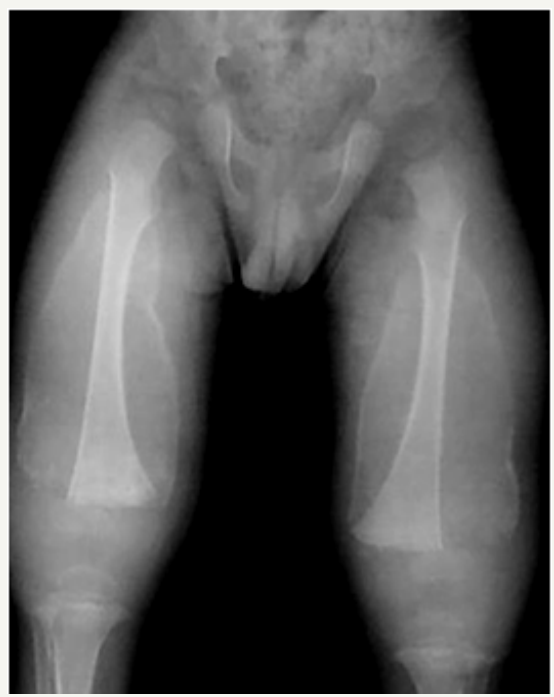

Figure 8a: Scurvy showing subperiosteal hematomas and subluxation at the knee joint.

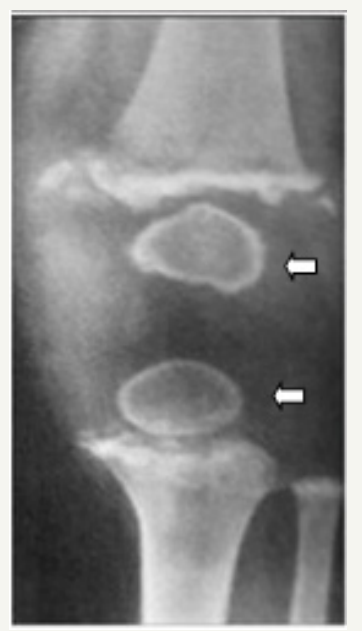

Figure 8b: showing Wimberger's ring sign. Dense outer ring with central lucency.

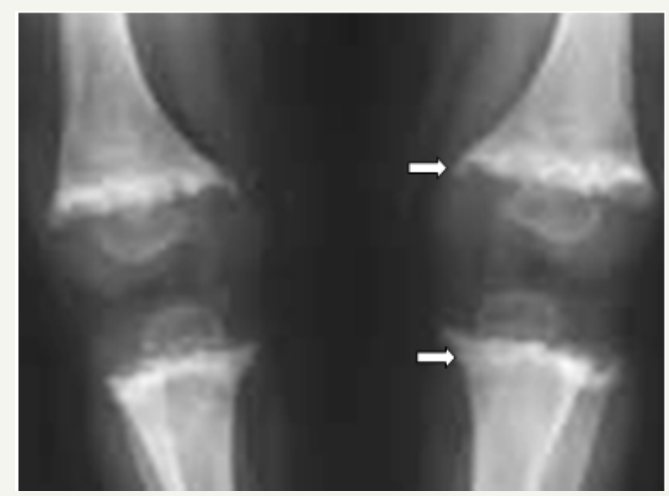

Figure 8c: Scurvy- both knees showing the Frankel's lines and Pelkan spurs.
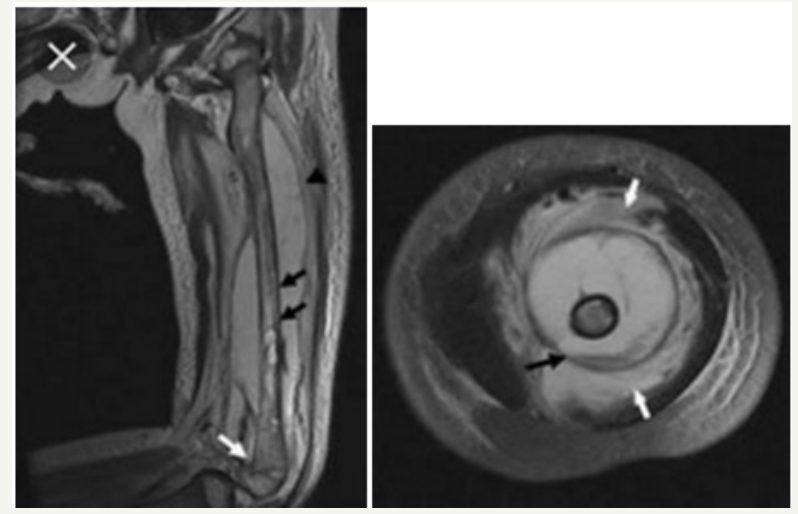

Figure 8d: SCURVY MRI showing subperiosteal hematomata.

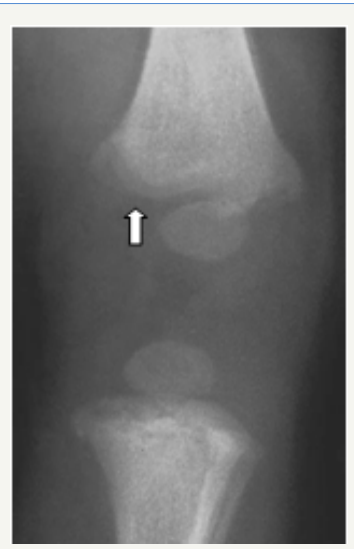

Figure 9: Non accidental injury showing a bucket handle fracture.

On occasion, a combination of vitamin deficiencies may be encountered, in which case both rachitic and scorbutic findings may be noted on radiographs.

Generally, conventional radiographs are enough and advanced imaging such as CT and MRI are superfluous. However, MRI may depict better pictures and show marrow changes (Figure 8).

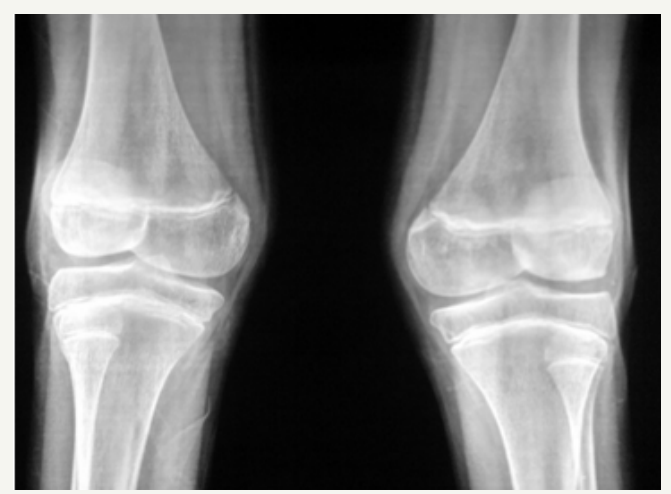

Figure 10: Osteoporosis in a $12 \mathrm{yr}$ old child, note the lucency of the matrix with cortical thinning.

In the differential diagnosis, non accidental injury in children may be considered. In non accidental injuries, multiple fractures occurring at different times are noted. Bucket handle fracture is a common finding [1]. Elicitation of history is essential (Figure 9). 
Osteoporosis in children: Unlike in adults primary osteoporosis in children is very rare. Osteoporosis is a metabolic disorder. The bones become weak and hence break easily. Juvenile osteoporosis may be primary or secondary; the cause of primary is unknown and is called idiopathic juvenile osteoporosis. Radiological findings include lucency of the bones with pathological fractures $[8,9]$. However, it is too late to diagnose and grade osteopenia by conventional radiology (Figure 10). In adults, bone mineral density (BMD) is measured by dual energy bone absorptiometry. This is not very reliable in children.

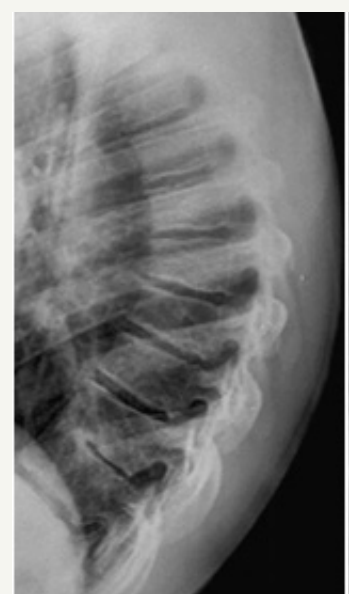

a

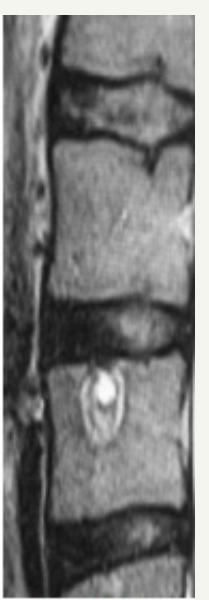

b- MRI
Figure 11a \& b: Scheurmann's disorder, note the Schmorl's nodes on MRI.

There is another kind of osteoporosis of the vertebrae

Table 5: The radiographic features. associated with Schmorl's nodes and kyphosis called Schuermann's disease (Figure 11a-11b).

\section{Toxic Effects on Skeleton}
1) Vitamin A/D
2) Lead
3) Fluorine
4) Steroids

\section{Hypervitaminosis A}

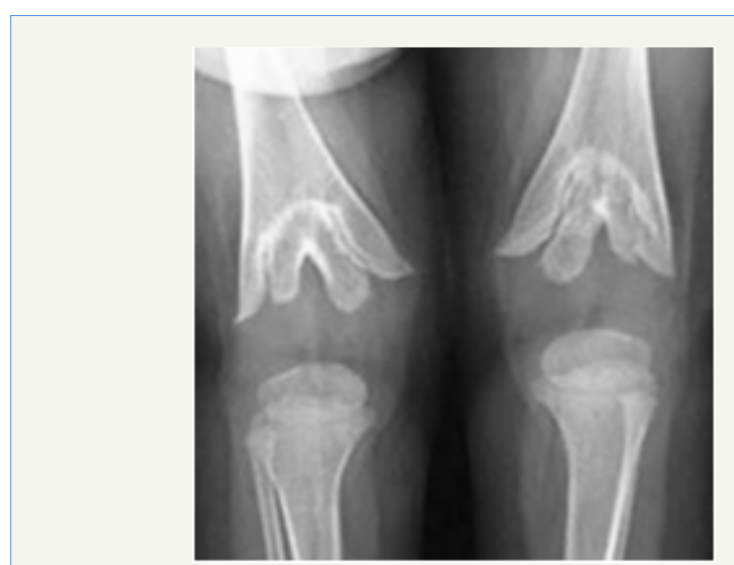

Figure 12a: Hypervitaminosis A, note the coned epiphyses.

It is very rare but uneducated mothers may go on giving high doses of Vitamin A. Radiological findings include coned epiphysis with triangular notching of metaphysic (Figure 12a). Periosteal reactions are also noted along ulna and 5 th metatarsal bones

\begin{tabular}{|c|}
\hline The Radiographic Features \\
\hline Generalised osteopaenia \\
\hline Periosteal reaction and subperiosteal hematoma due to subperiosteal haemorrhage (Figure 8a) \\
\hline Haemarthrosis \\
\hline Wimberger's ring sign- circular, opaque radiologic shadow surrounding epiphyseal centres of ossification, which may result from bleeding (Figure 8b) \\
\hline Frankel's line: dense zone of provisional calcification (Figure 8c) \\
\hline Trümmerfeld zone: lucent metaphyseal band underlying Frankel's line \\
\hline Pelkan spur: metaphyseal spurs which result in cupping of the metaphysic (Figure 8c). \\
\hline
\end{tabular}

\begin{tabular}{l}
\hline 12b: Hypervitaminosis A, periosteal reaction along \\
Figure \\
the medial side of ulna.
\end{tabular}

simulating Caffey's infantile hyperostosis $[1,9,10]$ (Figure 12b).

\section{Hypervitaminosis D}

This is also rare but often seen with overdose of Vitamin D in treating rickets [11]. Radiologically dense metaphyses are noted with osteoporosis of rest of bones (Figure 13a \& 13b).

\section{Plumbism}

Lead toxicity leads to plumbism, where the children suck the Chinese matel toys which are lead coated. Radiographic features of lead toxicity in children include, bands of increased density at the metaphyses, can affect any metaphysis [12]. Involvement of proximal fibula and distal ulnar metaphysis is highly suggestive (Figure 14ab). Occasionally a bone in a bone appearance may be seen. 


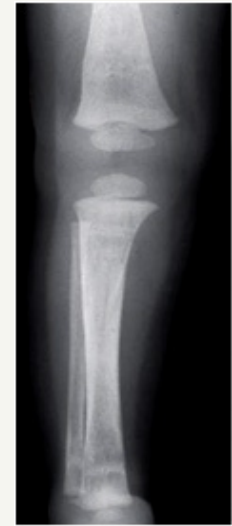

$a$

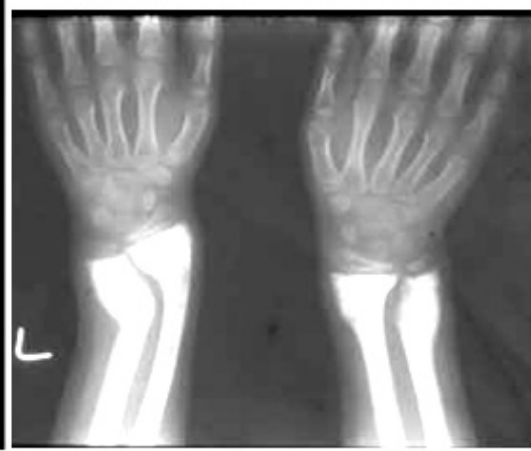

Figure 13a \& b: Hypervitaminosis- D, note the dense metaphyses with osteoporosis of the rest of the bones.

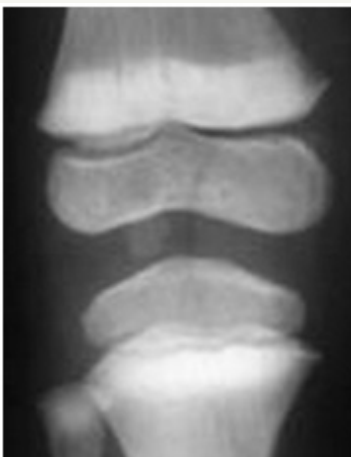

a

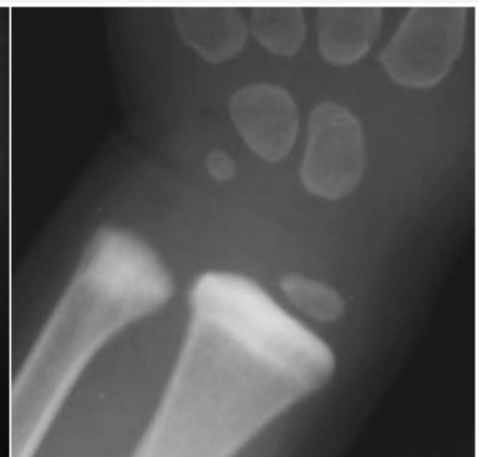

b
Figure 14a $8 \mathbf{b}$ : Lead toxicity; note the dense metaphyseal bands and cortical sclerosis of epiphyses and carpal bones.

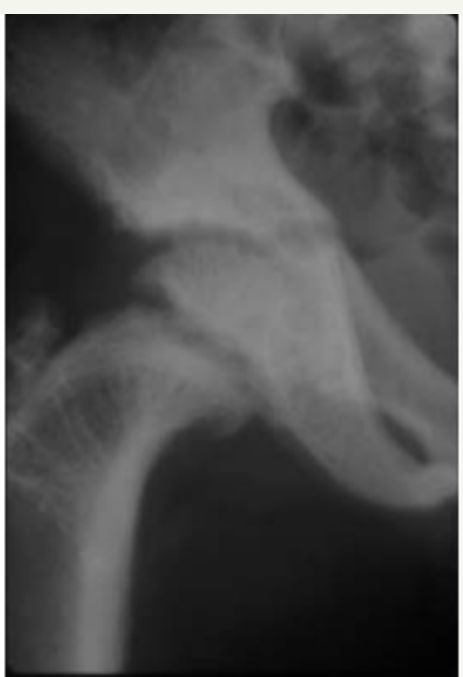

Figure 15: Fluorosis, rachitic changes with dense bones.

\section{Fluorosis}

FLUORIDE EXCESS by 1.8 PPM for a length of time in endemic areas may produce changes in pediatric skeleton. The radiological findings include increased sclerosis of bones, rickets and stress lines in the growing bones [13] (Figure 15).

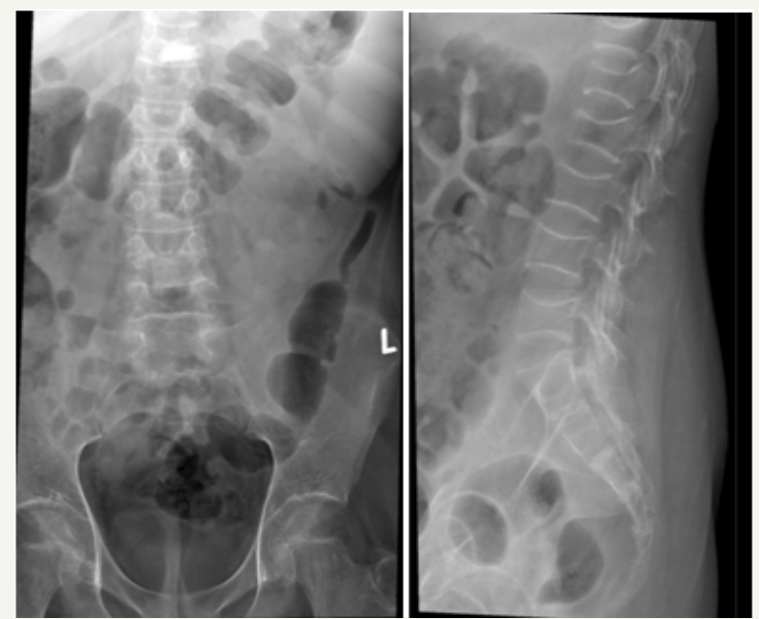

Figure 16: Fish mouth/Cod fish vertebra secondary to osteoporosis.

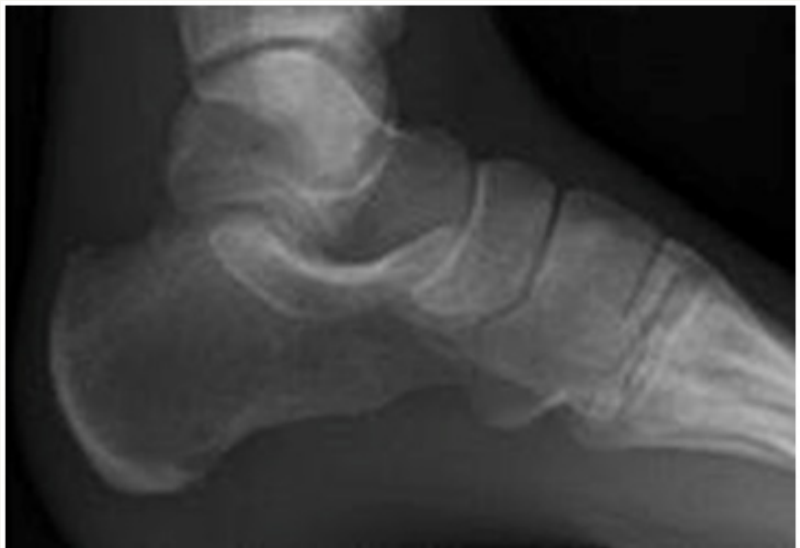

Figure 17: Anorexia nervosa - Gelatinous Transformation of bone marrow

\section{Steroids}

Use of steroid medications is not uncommon in pediatric practice. The radiological findings include: osteoporosis, avascular necrosis, stress fractures and infarcts of bone. The vertebral end plates show concavity resembling fish mouth vertebrae (Figure 16). In advanced cases, vertebral fractures are noted [14].

\section{Antiepileptic drugs}

Antiepileptic drugs such as dilantin sodium may produce rachitic changes due to induced microsomal P- 450enz and decreased Vitamin D. Radiological findings for similar to those noted in nutritional rickets.

Starvation and Anorexia nervosa: In these disorders osteoporosis is noted with bone marrow changes [15] (Figure 17).

\section{Summary}

Nutritional disorders include nutritional deficiencies as well as hyperdoses of vitamins and minerals. The major deficiencies include lack of vitamin D and C. The radiological characteristics are described with illustrations. Similarly, toxicities such as 
hypervitaminosis A and D, plumbism, steroids and fluorides are described with characteristic radiological findings.

\section{Acknowledgement}

NIMS (HYD) AND KREST MUSEUM (Shaikpet, HYD).

\section{Conflicts of interest}

Author declares no conflicts of interest.

\section{References}

1. Brian D Coley (2013) Caffey's pediatric diagnostic imaging. Elsevier/ Saunders 1.

2. Gaillard F (2015) Rickets. Radiopaedia, Melbourne, Australia.

3. Schulthess GK, Zollikofer CL (2005) Musculoskeletal diseases, diagnostic imaging and interventional techniques. Springer Verlag, Berlin, Germany.

4. Reeder MM, Felson BR (2003) Felson's gamuts in radiology, comprehensive lists of roentgen differential diagnosis. Springer Verlag, Berlin, Germany.
5. Priya Chudgar - Rickets Radiology; Pediatric on call- child health care.

6. Cheema JI, Grissom LE, Harcke HT (2003) Radiographic characteristics of lower-extremity bowing in children. Radiographics 23(4): 871-880.

7. Greenfield GB (1986) Radiology of Bone Diseases.

8. Jowsey J, Johnson KA (1972) Juevenile osteoporosis; bone findings in seven patients. J Pediatr 81(3): 511-517.

9. Mantravadi M (2016) Pediatric osteoporosis. Medscape, California, USA.

10. Pamela M. Vitamin D. Radiopaedia, Melbourne, Australia.

11. Henry K. Hypervitaminosis A. Radiopaedia, Melbourne, Australia.

12. Bruno Di M, Abhijit D Lead poisoning, Radiopaedia, Melbourne, Australia.

13. Christie DP (1980) The spectrum of radiological bone changes in children with Fluorosis. Radiology 136(1): 85-90.

14. Mushtaq T, Ahmed S (2002) The impact of corticosteroids on growth and bone health. Arch Dis Child 87(2): 93-96.

15. Jessica JK, Raul NU, Alejandro MH (2013) Imaging Findings in Eating Disorders. AJR Am J Roentgenol 200(4): W328-W335.
Your subsequent submission with Crimson Publishers will attain the below benefits

- High-level peer review and editorial services

- Freely accessible online immediately upon publication

- Authors retain the copyright to their work

- Licensing it under a Creative Commons license

- Visibility through different online platforms

- Global attainment for your research

- Article availability in different formats (Pdf, E-pub, Full Text)

- Endless customer service

- Reasonable Membership services

- Reprints availability upon request

- One step article tracking system 